\title{
Aneurysm of Interventricular Septum with Aortic Valve Malformation in an Infant
}

\author{
P. MORTON, J. G. MURTAGH, AND M. D. O'HARA \\ From the Cardiovascular Unit, Belfast City Hospital, and the Department of Pathology, \\ The Queens University of Belfast
}

Aneurysm of the membranous septum is a rare condition. The majority of the one hundred and eight cases described in published reports has been reported at necropsy. Only a small proportion has been confirmed by angiography during life (Steinberg, 1957; Yang et al., 1969). It is our purpose to report a further case associated with an unusual aortic valve malformation, in an infant eight hours old.

\section{Case Report}

A male infant weighing $2.74 \mathrm{~kg}$. was born by normal delivery after an uneventful pregnancy. Two hours later he became distressed, and on examination shortly afterwards his appearance was grey with conspicuous indrawing of the lower costal margin and rapid grunting respiration. The remaining abnormal signs were confined to the cardiovascular system. The pulses were easily palpable and collapsing in character. The apex beat was displaced to the left and systolic and diastolic thrills were palpable. Auscultation revealed a presystolic triple rhythm, a grade IV ejection systolic murmur, and a grade IV diastolic murmur. The murmurs were audible all over the praecordium but were maximal in the third and fourth left intercostal spaces. A left atrial angiogram (Fig. 1) showed an aneurysm of the membranous septum, gross dilatation of the ascending aorta, and aortic valve deformity. There was considerable aortic insufficiency through an aorto-left ventricular communication (arrow). The infant died approximately 18 hours after birth.

Necropsy findings. The abnormal findings were confined to the heart which weighed $59 \mathrm{~g}$. (expected weight $17.9 \mathrm{~g}$.$) . The right heart was normal apart from slight$ hypertrophy of the right atrium and ventricle. A large patent ductus arteriosus was present. The left atrium, mitral valve, and chordae were normal. The left ventricle was grossly hypertrophied (measuring up to $14 \mathrm{~mm}$. in thickness) with conspicuous endocardial thickening. In the membranous interventricular septum beneath the aortic valve there was a "diverticulum", the neck of which was $1.5 \mathrm{~cm}$. in diameter. This passed upwards and to the right, lying behind the pulmonary outflow tract and causing partial obstruction to the infundibular area. The aortic valve was atretic with three rudimentary cusps and severe stenosis. To the right of the valve there was a circular opening, $4 \mathrm{~mm}$. in diameter, connecting the aorta with the cavity of the left ventricle. Below the aortic opening of this channel there was a small crescentic pocket of endocardium resembling a valve. The ascending aorta was dilated (Fig. 2).

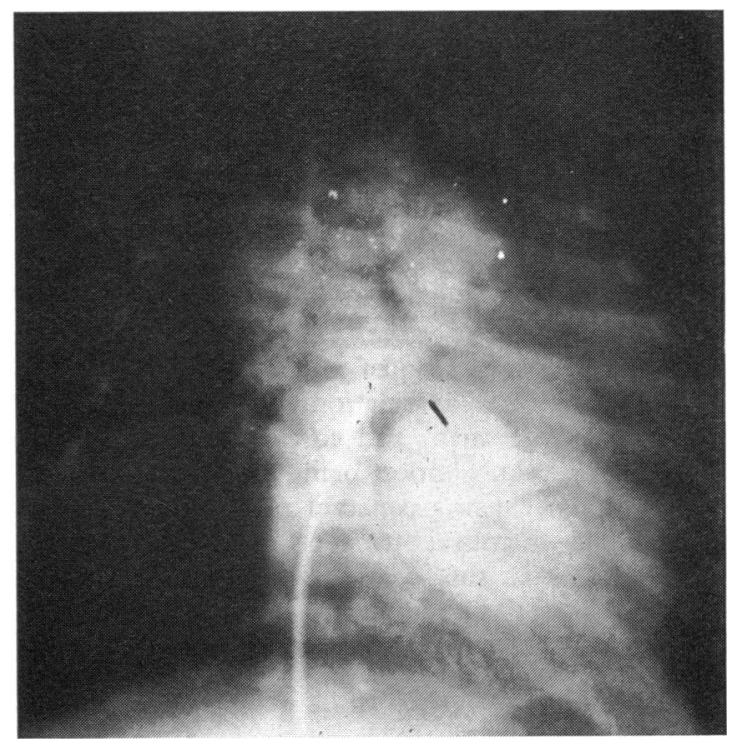

FIG. 1.-Left atrial angiogram showing aneurysm of the membranous septum, aortic dilatation, and aortic regurgitation (arrow). 

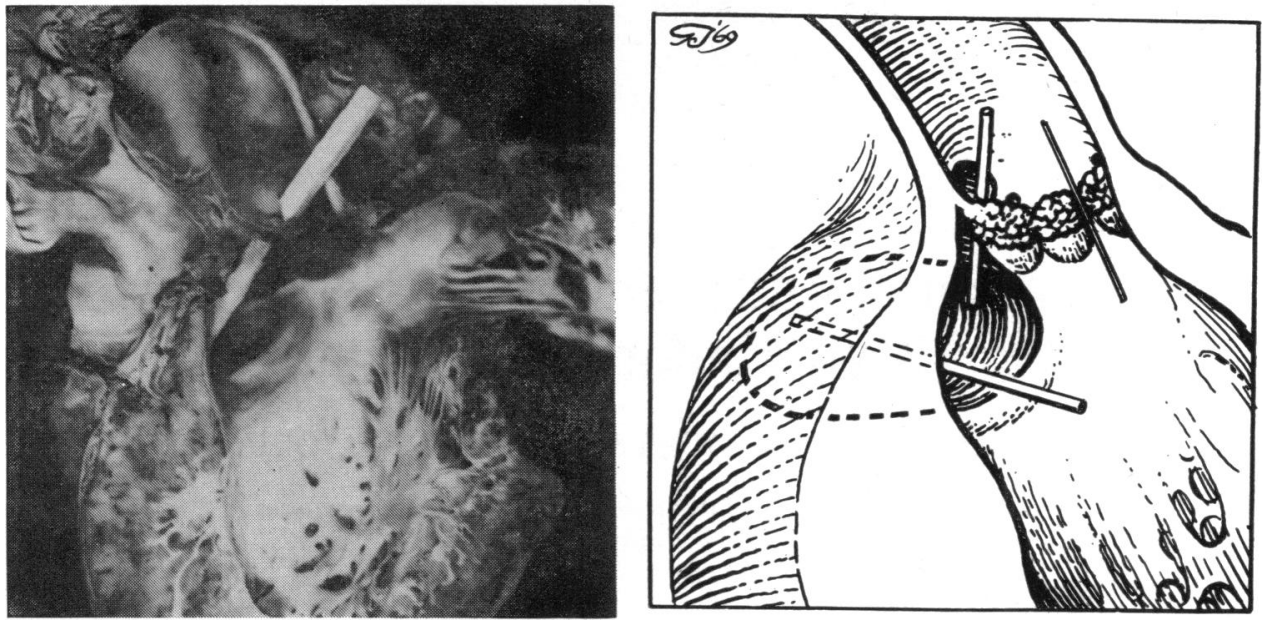

Fig. 2.-The aneurysm, the atretic and stenosed aortic valve, and the aorto-left ventricular communication. The gross left ventricular hypertrophy and fibroelastosis are also shown.

Histological examination of the left ventricular myocardium revealed conspicuous endocardial thickening, mainly due to elastic tissue.

\section{Discussion}

Aneurysm of the interventricular septum has been reported mostly in children or adults who died of unrelated disease (Lev and Saphir, 1938). A few reports ascribe death to arrhythmias where it was considered that the aneurysm interfered with the conduction mechanism (Rogers, Evans, and Domeier, 1952; Clark and White, 1952). No previous cases have been described in association with fibroelastosis. It has been suggested (Mall, 1912) that aneurysms can result from displacement of the membranous septum by an anomalous portion of the aorta and so can occur with malformations of the aorta and aortic valve. Leckert and Sternberg (1950) reported a case of aneurysm of the membranous septum in association with a penetration of the right aortic cusp, and aortic insufficiency, the gross aortic regurgitation being responsible for the aneurysm by causing constant pulsion and stretching of the membranous septum. It also seems possible that in this case the aneurysm may have resulted from the anomalous aortic valve and adjacent aorto-left ventricular communication.

\section{Summary}

A case of aneurysm of the interventricular septum with an unusual aortic valve deformity is described in an infant 8 hours old. These malformations are rare and few have been diagnosed during life.

The authors wish to express their thanks to Dr. M. J. L. Frazer, Senior Consultant Paediatrician, Belfast City Hospital, for permission to investigate and report this case.

\section{References}

Clark, R. J., and White, P. D. (1952). Congenital aneurysmal defect of the membranous portion of the ventricular septum. Circulation, 5, 725.

Leckert, J. T., and Sternberg, S. S. (1950). Congenital aneurysm of the membranous interventricular septum with unique anomaly of the pulmonary vessels. Amer. Heart f., 39, 768.

Lev, M., and Saphir, O. (1938). Congenital aneurysm of the membranous septum. Arch. Path., 25, 819.

Mall, F. P. (1912). Aneurysm of the membranous septum projecting into the right atrium. Anat. Rec., 6, 291.

Rogers, H. M., Evans, I. C., and Domeier, L. H. (1952). Congenital aneurysm of the membranous portion of the ventricular septum: Report of two cases. Amer. Heart f., 43, 781.

Steinberg, I. (1957). Diagnosis of congenital aneurysm of the ventricular septum during life. Brit. Heart $\mathcal{F}$., $19,8$.

Yang, S. S., Maranhao, V., Ablaza, S. G. G., Morse, D. P., and Goldberg, H. (1969). Aneurysm of the membranous portion of the ventricular septum. Amer. $\mathcal{F}$. Cardiol., 23, 83. 